\title{
The church as a HIV-competent faith community: An assessment of Christian AIDS Bureau for Southern Africa's Churches, Channels of Hope training
}

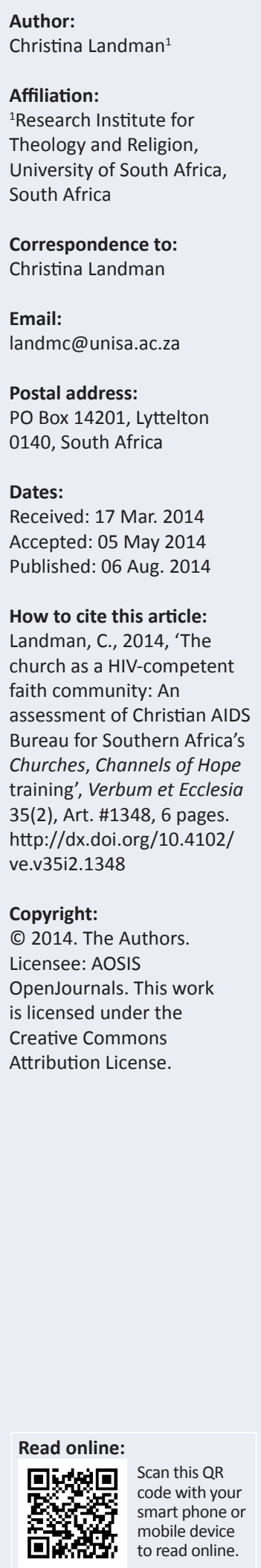

Julian Müller has envisioned the praxis of theology, from a postfoundational point of view, to develop in two movements: engagement in a community that leads to 'real contextual outcomes' and the establishment of new traditions as deconstructed discourses that move beyond single communities. This article assesses the Churches, Channels of Hope $(\mathrm{CCOH})$ training of the Christian AIDS Bureau for Southern Africa (CABSA) in terms of the two criteria laid down by Müller. Firstly, do they successfully train their facilitators to skilfully empower their faith communities to become competent in dealing with people living with HIV? In other words, does the $\mathrm{CCoH}$ training lead to 'real contextual outcomes'? Secondly, are the deconstructed social discourses put in place by the $\mathrm{CCOH}$ training that focus on the 'new' Christian values of human worthiness and agency able to constitute a contra-culture that will move beyond the boundaries of specific contexts? After the $\mathrm{CCOH}$ facilitator's manual and a report on the facilitators' reaction to the training course have been studied, it was found that the $\mathrm{CCOH}$ training embodies 'HIV competency' in practices and discourses that can indeed be called 'contextual' as well as 'contra-cultural' although they lack some much-needed skills in reading the Bible from a non-fundamentalist point of view and conducting their impact studies in a more sophisticated and non-reductionist way.

Intradisciplinary and/or interdisciplinary implications: The article wants to make a contribution to HIV discoursing over a wide range of disciplines. The lifestyle changes and spiritual healing of the $\mathrm{CCOH}$ training that is assessed here inform the fields of counselling, life skills, law and gender. The proposed contra-culture and alternative discourses at stake touch on the fields of primary, secondary and, indeed, tertiary education.

\section{Introduction}

This article is dedicated to Julian Müller who, until his recent retirement, was professor in practical theology at the University of Pretoria in mid-northern South Africa. Müller has, in a vast variety of publications, used postfoundationalism as a preferred theory in engaging with HIV and AIDS (Müller 2004, 2005, 2009; August \& Muller 2011). In these works, Müller describes postfoundationalism as a theory of praxis that takes both the contextuality and the beyondness of the (co-)researched into account. The praxis of this theory not only requires 'real contextual outcomes' (Müller 2004:294) but also the establishment of new traditions - such as life-giving, name-giving and language - that will transcend the context researched to open up futures for other contexts.

The contra-culture thus established in communities of faith is researched in this article with reference to the training course, Churches, Channels of Hope $(\mathrm{CCOH})$ as presented by the Christian AIDS Bureau for Southern Africa (CABSA) with headquarters in Wellington, South Africa.

There is a reason for choosing $\mathrm{CCoH}$ for this evaluation. $\mathrm{CCoH}$ aims to equip faith communities from an ecumenical perspective with competency to deal with people living with HIV, to focus on spirituality as a bodily asset and to present a Christian response to HIV and AIDS as one that needs to be managed by humans. In this claim, it is unique in its presentation and presents itself for assessment.

$\mathrm{CCoH}$ training is held with 'facilitators' in a variety of countries in Africa. The 'facilitators' are representatives from churches and other faith-based organisations from African countries who report for training in competency regarding people living with HIV. Through its partners, AIDSLink and WorldVision, the course is presented worldwide. The training lasts 7 days. The evaluation of the course focuses on the facilitator's manual (CABSA 2010). 
The article will proceed through three phases of assessment. Firstly, the article assesses the shifting of contextual discourses to contra-cultural discourses as presented in the $\mathrm{CCoH}$ training manual. 'Contra-cultural discourses' do not refer to discourses that are hostile to cultural practices. Establishing a contra-culture entails inviting alternative discourses into a community that is held captive, in this case, by faith discourses that are harmful to its members living with HIV.

This article is of the view that all members of a faith community are affected by HIV and AIDS in one way or another. Consequently, I find helpful the questions that Vhumani Magezi (2010:35-41) suggests to ask of faith communities in order to assist in establishing alternative HIV and AIDS discourses and practices. The questions assist communities of faith to reflect on ministries that are new and are resisted by members of the faith community. These are questions such as the following:

- What kind of Christian ministries are most uncomfortable to the church and why?

- What can happen if one member of a congregation stands up and says: 'I am HIV positive'?

This article also takes note of alternatively strategies for people taking care of other people living with HIV as proposed by Magezi (2010:36). These strategies are aimed at inviting change into a community and include strategies such as caretakers caring for people in their relationship with other non-symptomatic members and not in isolation, caretakers not engaging in excessive and unsustainable care and caretakers using a 'crisis as an opportunity for bringing change to the entire system' (Magezi 2010:36).

Secondly, the impact that the training of facilitators who attended the $\mathrm{CCoH}$ courses has on faith communities is assessed. This is done by answering questions such as the following:

- Were the questions asked to the facilitators non-reductive and capable of retrieving their lived experience as multifaceted?

- Are their experiences reflecting the aims of the training as explained in the first section of this article?

Thirdly, in a final round of assessment and as a summary of research findings already described in the first two parts of the article, the article will assess how, if indeed, competency regarding people living with HIV is embodied in the alternative discourses presented by $\mathrm{CCoH}$ training. This summarising assessment will include, firstly, the proposed competency of healing the physical body through medical facts and interventions as well as through practical structures and processes put in place by communities of faith. Secondly, the competency of healing the symbolic body will be assessed, that is, healing brought about through the shifting of societal discourses on the sexuality, health, dignity and durability of the body affected by HIV and AIDS. Thirdly, the competency of healing the political body by giving agency to the body affected by HIV and AIDS will be discussed. Finally, the competency of healing brought to the spiritual body through healthy spiritual discourses and liturgies will be on the table.

\section{Contra-culture in context}

Müller (2004:300) describes the method of his 'postfoundationalist practical theology' in seven steps, here summarised in two movements. Firstly, the context of the researched is described and interpreted with the collaboration of the researched as co-researchers with a focus on their experiences of God's presence in their context. Secondly, this interpretation is placed in the broader context of (interdisciplinary) traditions of interpretation that may be alternative and contra-cultural and then it is developed beyond the context of the researched. Müller (2004:294) gives special attention to language as a vehicle of contra-cultural values.

In this section, the context and contents of the Churches, Channels of Hope will be described and assessed as to the contra-cultural discourses they present as well as to the alternative church practices established that, according to the course, will lead to churches that are competent in dealing with people living with HIV.

In order to establish churches that are competent in dealing with people living with $\mathrm{HIV}, \mathrm{CCoH}$ commits to seven contracultural discourses and practices which are given towards the end of the manual as seven tools for assessing competency in dealing with people living with HIV. CCoH will now be assessed in terms of each of its assessment criteria concerning the alternatives offered.

\section{A relevant and responsible use of the Bible}

$\mathrm{CCoH}$ uses biblical symbols such as salt and light to encourage Christians to bring hope and new life to a broken world where decay and death prevail. It uses the values expressed in the letters of the New Testament as guiding principles to practise an alternative lifestyle in communities that are incompetent in dealing with people living with HIV. Churches will be competent to deal with people living with HIV when they are motivated by the love of Christ (2 Cor 5:14), take on the responsibility of breaking the silence (Eph 4:15), find their identity in being part of the body of Christ (1 Cor 12:12) and base their relationships on upholding the dignity and worth of every human being (G1 3:28) (CABSA 2010:4.1/1-12).

Has $\mathrm{CCoH}$ succeeded in providing a Biblical language for speaking about HIV and AIDS contra-culturally? Fundamentalism is the unproblematic transfer of Biblical contents to present contexts. This is indeed the method used in $\mathrm{CCoH}$. However, the aim of using fundamentalism as a method to form a foundation for current societal values that counteract practices of stigmatisation and indifference, based on the values of the first Christians who challenged the culture of an insensitive and cruel society, is here assessed 
as a responsible - albeit fundamentalist - use of the Bible. A new language, albeit in line with fundamentalist practices, is being formed for churches that are competent to deal with people living with HIV in order to construct new discourses that will undermine present discourses of shame and stigma.

\section{An understanding of vulnerabilities}

$\mathrm{CCoH}$ acknowledges that people are vulnerable to HIV infection when they are deprived of control over their own bodies. Gender discourses that give (divine) control to men over women's bodies strengthen women's vulnerability to infection. Children are vulnerable when adults exercise undue control over infant bodies. Poor people are vulnerable when they do not have the means for defending or feeding their bodies or for buying anti-retrovirals.

Does $\mathrm{CCOH}$ succeed in deconstructing the discourses strengthening the vulnerability of the poor, women and children? The course indeed does not adequately shift these discourses to healthy alternatives, and only an introduction to power relationships between men and women as a possible cause of the vulnerability for HIV infection for both men and women is given (CABSA 2010:4.5/1-8).

In favour of the course, it needs to be said that facilitators are encouraged to discover their own vulnerabilities in dealing with people who are infected with HIV. These vulnerabilities include discourses and practices of stigmatisation and discrimination that need to be addressed both within facilitators themselves and within their faith community (CABSA 2010:4,3/1-6). The role of Christians in stigmatising those affected by HIV is acknowledged and alternative Christian discourses are encouraged, including the use of non-judgmental language, public advocacy for the rights of people living with HIV, showing care and encouraging people who are open about their HIV and AIDS status to share their stories with others (CABSA 2010:4.3/7).

An assessment of the course in this regard will point out that $\mathrm{CCoH}$ grows sensitivity amongst its students for the vulnerabilities of society in the face of infection with HIV. However, these vulnerabilities are described in the now already well-known categories of gender, childhood and poverty. A more varied and informed presentation of the causes of vulnerability should be made. People are not only vulnerable to HIV infection because they are women, children and/or poor people. They are also vulnerable because of loneliness, discourses on coupledom, a need to belong and cultural practices. These causes of HIV infection need to be addressed in a course on HIV and AIDS.

\section{Leadership}

According to $\mathrm{CCoH}$ every believer is a leader and facilitators obviously doubly so. Leading a church to competency in dealing with people living with HIV encompasses three steps. Firstly, one is to discover oneself, who you are, and reclaim your life-story as a journey with God. Secondly, one is to discover God in one's faith community and identify what God has already done in the church. Thirdly, one has to discover God's dream for the world, which is for the churches to be channels of hope and to move towards greater competency in dealing with HIV (CABSA 2010:5/2).

God's introduction into the training programme here is sudden but not unexpected. Throughout the training, God was present in the acknowledgement of the compassion of Christ as an example for leading churches to be competent in dealing with people living with HIV. Also, God is introduced here in a leadership role by discovering God's working in the world. God is not presented as a deus ex machina to claim competency programmes in dealing with people living with HIV for Christianity.

However, the introduction of God here is slightly too supernatural to be either alternative or relevant. An alternative discourse on divine participation in making churches competent should rather have been based on the work believed to be done by Jesus Christ when living with people who have been oppressed, stigmatised and misled by certain religious discourses and who were desperately in need of healing on different levels.

\section{Responsible community interaction}

To network with other churches and to expand this networking to all faith-based organisations is, for $\mathrm{CCOH}$, an important competency in dealing with people living with HIV. Practices in this regard are encouraged and described (CABSA 2010:5/20). Moreover, trainees are presented with job-creation training (CABSA 2010:5/15) which is, of course, a very relevant and healthy practice within competency in dealing with people living with HIV.

Not much criticism can, of course, be lodged against training done from these insights. However, more is needed. A management programme is needed to assist churches through the facilitators - to care for people affected by HIV through preaching, home visitations, counselling, the provision of day care and accommodation for the families who come to assist them. Writing proposals for money to run projects of this nature whilst cooperating with faith-based organisations (FBOs) and other community organisations should be part of the training.

\section{Compassionate justice}

Compassionate justice is about upholding and restoring the dignity and worth of every human being by speaking the truth in love and advocating for various services, rights and principles in our communities. (CABSA 2010:5/20)

Defining compassionate justice thus, facilitators in the $\mathrm{CCoH}$ programme are made aware of their responsibility to advocate for the right of people infected with HIV to have access to treatment as well as to the competency of faith communities. Compassionate justice also 
means addressing both a reluctant society and an as yet incompetent faith community.

To the credit of $\mathrm{CCoH}$, it must be said that they do not look at proclaiming the 'truth' as a simple or innocent act. They also do not believe that believers have more access to 'truth' than anybody else. On the contrary, facilitators are confronted with 'tough stuff' and questions concerning Christian advocacy are problematised (CABSA 2010:4.4/3-4). Should Christians support the decriminalisation of prostitution? Is it appropriate for churches to distribute condoms as part of a strategy to prevent the further spread of HIV? Should HIV-positive people be encouraged to engage in faith healing? Would advocacy for the availability of antiretroviral medication not compromise our faith in God's power to heal? These are some of the questions the facilitators are invited to contemplate.

Whilst compassionate justice is probably the aspect in which $\mathrm{CCoH}$ excels most in terms of alternative discoursing, it is also the field in which $\mathrm{CCoH}$ will have to care most for its facilitators. Sending the facilitators back to their churches to insist on churches getting involved in advocacy on issues of gender, the availability of medicine and the decriminalisation of prostitution and drug abuse, inter alia, may place the facilitator at risk of being ostracised. The facilitators will be asking churches to advocate for issues which the churches themselves have made worse in the past. $\mathrm{CCOH}$ should incorporate in the course training for the facilitators on how to deal with resistance and suspicion in the church and on how to put systems in place that would change the church's role in public advocacy. In short, facilitators will have to be empowered to address the challenges of contra-cultural life in the community and church.

\section{Compassionate care and support}

$\mathrm{CCoH}$ deals bravely with issues such as the participation of people living with HIV in church and community life, homebased care, treatment, physical care and the establishment of support groups for legal advice (CABSA 2010:5/20).

However, as was pointed out in the paragraph on responsible community interaction, this practical training is neither thought out well nor is it structured enough in the $\mathrm{CCOH}$. Training in how to put together a management plan to deal with people living with HIV is needed to structurally care for people affected by HIV. Whilst it is difficult to train facilitators in basic counselling skills in the course of 7 days, time should be allotted to familiarise facilitators with basic counselling practices and with dealing with traumatisation in situations related to HIV and AIDS.

\section{Compassionate prevention}

In terms of prevention, the commonly known discourse of the $\mathrm{ABC}$ of HIV prevention - abstinence, be faithful and condoms - is shifted in $\mathrm{CCOH}$ towards a discourse that unites the community and puts those at risk on a more compassionate road of prevention. ABC is replaced by SAVE, that is, safe(r) practices, access to treatment, voluntary testing and empowerment. This is a combination of the community taking the responsibility for creating opportunities for treatment and testing, individuals managing their own sexual health and the church empowering people through a discourse of their unalienable worth and dignity in God's eyes (CABSA 2010:4.2/1-9).

Forthwith, the inevitable question is asked whether 'unlawful' sex - that is, sex before and outside of marriage - can be considered to be 'safe' sex (CABSA 2010:11-38). The traditionally ecclesiastical answer of 'sex with a married partner' is given, but $\mathrm{CCoH}$ (at least) problematises the issue. Also, (male) circumcision and masturbation (and condoms) are presented as strategies to prevent the spread of HIV and stands contra the culture of churches' traditional silence on or rejection of these practices (CABSA 2010:11-38).

Evaluating $\mathrm{CCoH}$ in terms of the alternative strategies presented to prevent HIV infection shows a significant shift in $\mathrm{CCoH}$ towards prevention strategies that are usually judged negatively by the church on the grounds of a person's body belonging to his or her marriage partner. Thus, the church usually rules out masturbation and condoms. However, when $\mathrm{CCoH}$ acknowledges only marriage as a space for engaging in sex, it does not take into account the context and realities of millions of poor and migrant people who do not have access to sex in marriage. Marriage is the luxury and prerogative of middle and upper-class people who can pay lobola and support families. Alternative discourses on 'lawful' sex are needed for very poor people, migrants and people who are single because they have not been invited into marriage by a partner. $\mathrm{CCOH}$ is not providing these much needed contra-cultural discourses for alternative contexts.

\section{The interpreted experiences of the 'co-researchers'}

In a report on the impact of the CCoH course released in 2013, director Lyn van Rooyen (Janssen 2013:3) states that CABSA has trained 735 facilitators in their $\mathrm{CCoH}$ courses over the past 10 years and that, through the facilitators, an estimated half a million people affected by HIV have benefited from the course.

CABSA annually requests feedback from the facilitators in the form of impact reports. These reports represent the voices of the facilitators as 'co-researchers' to the study to establish the impact of $\mathrm{CCOH}$. They will be used here to assess $\mathrm{CCoH}$ as being, firstly, contextual in its training and, secondly, successful in its training of facilitators to move beyond the local cultures of stigmatisation, exclusion and fear and establish a contra-culture of inclusion and worthiness as far as HIV is concerned.

Rhodé Janssen has published in 2013 the results of 72 impact reports that represent $10 \%$ of the facilitators trained in $\mathrm{CCoH}$ 
over the last decade. Assuming that these impact reports are representative of the voices of the 'co-researchers', Janssen's report, 'Analysis of impact reports of trained churches channels of hope facilitators in their local communities in 2012, and report of churches channels of hope facilitators training July 2013', will here be used to assess $\mathrm{CCoH}$ for both its cultural and contra-cultural contributions. As the title of the report indicates, it also contains information on interviews held with facilitators before and after the July 2013 training.

Firstly, the questions asked to the facilitators need to be assessed. Two sets of questions need to be asked here. Firstly, are the questions non-reductive and successful in inviting the interviewees to share their lived experiences of $\mathrm{CCOH}$ as multi-faceted? On the one hand, it can indeed be said that the questions invited the facilitators to share their experiences and reflect on the impact $\mathrm{CCOH}$ has made on both their own lives and those of others. On the other hand, the questions are too generic and also too complicated and double-barrelled with the result that the facilitators gave the generic answers they thought were expected from them (e.g. 'How would you describe the impact of the $\mathrm{CCoH}$ programme on your life since you attended the training?' invited answers such as 'CCoH opened my eyes and made me bold').

A second set of questions needs to be asked. Do the questions set to the facilitators reflect the (seven) aims of $\mathrm{CCoH}$ training as set by themselves and explained in the first part of this article? The aims of the $\mathrm{CCoH}$ training is to equip facilitators in guiding and supporting churches to be competent in dealing with people living with HIV, use the Bible responsibly, understand vulnerabilities, encourage leadership, interact with the community and engage compassionately with justice, care and prevention. Again, by way of assessment, it needs to be said that the questions do not assist the facilitators to focus on these issues but rather invite them to quantify the impact of the $\mathrm{CCoH}$ course in terms of how many workshops and other tangible activities they have arranged.

Secondly then, the answers of the facilitators on the contextuality of their contributions - unhappily called 'interventions' in the report - will be used to assess the $\mathrm{CCoH}$ training. The question 'What was the biggest highlight or most precious experience you had as channel of hope in the last year?' invited specific answers such as holding workshops and starting focus groups - and giving medical help, which point to community involvement as 'real contextual outcomes' (Figure 3 in CABSA 2010). Further questions invite the facilitators to display their own growing awareness of the community in which HIV and AIDS have found space to stay (Figures 4, 5 and 6 in CABSA 2010). Figures 7-9 (CABSA 2010) indicate that, in almost twothirds of cases, follow-ups were done within 3 months after an 'intervention' such as a workshop. In short, assessing the contextuality of the facilitators and their training, the data point to a positive assessment in terms of facilitators accessing the contexts in which they work by identifying the social discourses that keep the community captive through HIV and AIDS, and by practically addressing the needs of the community through medical and social aid as well as through knowledge.

Thirdly, I shall now assess the answers of the facilitators pointing to the construction of new and healthy contracultural discourses that go beyond one context only. The facilitators indeed indicated that their main contribution to society lay not only in the biomedical knowledge conveyed ( $9 \%$ of their contribution) but in the social knowledge that was communicated and specifically in the deconstruction of the harmful social discourses that maintain HIV and AIDS, the latter constituting 30\% of their work (Figure 1 in CABSA 2010). They also indicated that 'deconstruction' starts with oneself, to become an ongoing source of healthy change visà-vis HIV and AIDS discoursing (Figure 2 in CABSA 2010). This, too, points to a positive assessment. When discourses are shifted and rescoped and when people are given a healthy language to talk about their pain and their vulnerability as well as their agency and hope, a contra-culture that spreads across communities comes into being.

Summarising this section, there is a chance that facilitators gave answers to questions that were aimed to please the trainers. This was caused by questions being too generic and too much aimed at quantity. However, the facilitators showed an awareness of the needs and the captivity of the contexts in which they were working. They furthermore displayed skills in practically implementing spaces, like workshops, to meet these needs and to enhance contra-cultural acts against harmful discourses. However, what CABSA still needs to produce is a report on how $\mathrm{CCOH}$ training has impacted specifically on the seven areas in which they want to bring change and in which they want to act contra the prevalent culture concerning discourses on HIV and AIDS. These areas are the use of the Bible, understanding vulnerabilities, empowering all people as leaders, community interaction and compassion in justice, care and prevention.

\section{An alternatively embodied tradition: Summary of findings}

Does $\mathrm{CCOH}$ succeed in embodying 'HIV competency' in its training? Embodying takes place in four distinct forms: physical, symbolic, political and spiritual. The assessment here of the $\mathrm{CCoH}^{\prime}$ s embodiment in these four forms of competency in dealing with people living with HIV also serves as a summary of the above research findings.

CCoH's physical embodiment of competency in dealing with people living with HIV is commendable in its variety of forms. They account for liturgies, workshops, support groups, testing, medical aid, knowledge and follow-ups. Bible studies that are held but, although alternative in outcome, still use the methods and insights of a literal, fundamentalist reading. Training in counselling and the handling of trauma 
is lacking. Following Müller and his line of thought, narrative pastoral counselling may be an option for $\mathrm{CCOH}$ to consider.

CCoH's symbolic embodiment of competency to deal with people living with HIV, too, is remarkable when compared to other courses that deal with HIV and AIDS from a traditional Christian point of view. Whilst 'Christian' approaches to HIV and AIDS may focus on the ABC of prevention and may point to God's punishment, $\mathrm{CCoH}$ has deconstructed these discourses towards healthier views of humans being worthy in God's eyes from whom they receive agency to stand up against HIV and AIDS. However, $\mathrm{CCOH}$ sometimes display a naivety when dealing with the causes of HIV and AIDS. The latter is not only caused by the engendering of bodies but also by loneliness, culture and coupledom.

The political embodiment of competency in dealing with people living with $\mathrm{HIV}$ presented by $\mathrm{CCoH}$ is, for this author, attractive. $\mathrm{CCoH}$ emphasises human agency, its Christian roots and the empowerment ensuing from this position. This stands in contrast to the pietism displayed elsewhere in the facilitator's manual, a pietism that is usually embodied in the helplessness and unworthiness of people.

Finally, the spiritual embodiment of competency in dealing with people with $\mathrm{HIV}$ in $\mathrm{CCoH}$ needs to be mentioned. $\mathrm{CCoH}$ presents as its strong point its affiliation to Christianity. Indeed, Christian sources are explored and embodied in the facilitator's manual. However, the course is in need of further theological input, especially in its integration of God into the embodiment of competency in dealing with people with HIV. The earthly life of Jesus and his praxis of dealing with people who were marginalised by the dominant discourses of the time urgently need to be embodied in $\mathrm{CCoH}$.

\section{Conclusion}

This research has assessed CABSA's CCoH training in terms of Julian Müller's two criteria for relevant postfoundational practices, namely 'real contextual outcomes' and the contraculturing towards life-giving discourses on HIV and AIDS. It was found that, the training of $\mathrm{CCOH}$ to empower facilitators and through them churches towards 'HIV competency' is successful in it physical, symbolic, political and spiritual embodiment. It was also found that these embodiments are contextual in that they address the challenges of the contexts in which HIV and AIDS discourses are prevalent, as well as contra-cultural in moving beyond fixed contexts that keep people captivated in harmful HIV and AIDS discourses and language. Finally, criticism was voices against the discourses on sexuality, gender and intimate relationships driving $\mathrm{CCoH}$ itself and the fundamentalism on which it is based. A final word of criticism against the $\mathrm{CCOH}$ training entails the fact that facilitators will experience a lack of skills to compile an AIDS-management programme in their faith communities.

In summary, $\mathrm{CABSA}^{\prime} \mathrm{C} \mathrm{CoH}$ training provides a healthy toolkit towards making faith communities competent in dealing with HIV and AIDS. It bases its life skills training on spiritual values that, although based on a fundamentalist reading of the Bible, empower both trainees and those affected by HIV and AIDS in a responsible way that can be supported academically as both contextual and contra-cultural.

\section{Acknowledgements Competing interest}

The author is a board member of CABSA but this has in no way influenced her assessment of their $\mathrm{CCoH}$ training course, neither has she benefitted financially from this research.

\section{References}

August, A. \& Müller, J.C, 2011, 'HIV and/or AIDS, migrant labour and the experience of God: A practical theological postfoundationalist approach', HTS Teologiese Studies/Theological Studies 67(3), Art. \#774, 6 pages. http://dx.doi.org/10.4102/ hts.v67i3.774

CABSA, 2010, 'Churches, channels of hope: Facilitator's manual', unpublished document.

Janssen, R., 2013, 'Analysis of impact reports of trained churches channels of hope facilitators in their local communitie s in 2012 and report of churches channels of hope facilitators training July 2013', unpublished CABSA Impact Report.

Magezi, V., 2010, 'Overcoming structural church barriers: Towards a systems assessment model for effective HIV and AIDS ministry', Journal of Theology for Southern Africa 137(July), 28-45.

Müller, J., 2004, 'HIV/AIDS, narrative practical theology, and postfoundationalism: The emergence of a new story', HTS Teologiese Studies / Theological Studies 60(1\&2), 293-306.

Müller, J., 2005, 'A postfoundationalist, HIV-positive practical theology', Practical Theology in South Africa 20(2), 72-88.

Müller, J., 2009, 'Transversal rationality as a practical way of doing interdisciplinary work, with HIV and AIDS as a case study', Practical Theology in South Africa 24(2), 199-228. 